\title{
Ovarian function and the establishment and maintenance of pregnancy in dairy cows with and without evidence of postpartum uterine disease
}

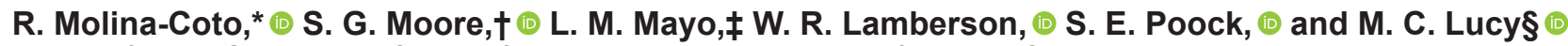 \\ Division of Animal Sciences and College of Veterinary Medicine, University of Missouri, Columbia 65211
}

\begin{abstract}
Uterine disease early postpartum reduces fertility during the breeding period. One potential mechanism involves the reduced functional capacity of the uterus to support pregnancy. A second potential mechanism involves damage to ovarian follicles associated with systemic inflammation. We categorized lactating Holstein cows into healthy $(\mathrm{n}=63)$ and diseased $(\mathrm{n}=39)$ uterus groups based on the percentage of polymorphonuclear neutrophils in the uterine lumen during the second and third month postpartum and evaluated the functionality of their ovaries and their capacity to establish and maintain pregnancy. Cows were enrolled in a timed artificial insemination protocol (Presynch Ovsynch) so that the first artificial insemination was approximately $75 \mathrm{~d}$ postpartum. Ovarian follicles and corpora lutea were counted and measured using transrectal ultrasound, ovulatory responses were assessed, and luteal phase progesterone concentrations were measured. Pregnancy was detected on $\mathrm{d} 18,20,22,25,32$, and 45 through chemical (d 18 to 25) or ultrasonographic methods (d 32 and 45). The percentage of cows ovulating during the Presynch period; the number, diameter, and ovulatory capacity of follicles during the Ovsynch period; and plasma progesterone concentrations following ovulation were similar for healthy and diseased cows. The initial period of pregnancy establishment (d 18 to 22) appeared to be unaffected by disease because a similar percentage of healthy and diseased cows were pregnant during this period. Embryonic loss occurred in both healthy and diseased cows after $\mathrm{d} 22$. Based on a relatively small number of pregnancies $(n=30$ healthy and
\end{abstract}

Received April 10, 2020.

Accepted June 17, 2020.

*Current address: Universidad de Costa Rica, Escuela de Zootecnia. San José, Costa Rica 11501-2060.

†Current address: Animal and Grassland Research and Innovation Centre, Teagasc Moorepark, Fermoy, Co. Cork, P61 P302, Ireland.

$\ddagger$ Current address: Integrative Biosciences PhD Program, Tuskegee University, Tuskegee, AL 36088.

$\S$ Corresponding author: lucym@missouri.edu $\mathrm{n}=17$ diseased), the cumulative embryonic loss after $\mathrm{d}$ 22 was greater in diseased compared with healthy cows. In short, uterine disease as defined in this study did not affect cyclicity, ovarian follicular growth, or plasma progesterone concentrations. Percentages of healthy and diseased cows that were pregnant were similar from d 18 to 22 after artificial insemination. Greater embryonic loss was observed after d 22 in diseased compared with healthy cows, but this observation was based on a small number of pregnancies and should be studied further in larger trials with greater statistical power. Key words: uterine disease, ovarian function, pregnancy

\section{INTRODUCTION}

Dairy cows face significant physiological and metabolic challenges during the periparturient period (LeBlanc, 2010; Gross and Bruckmaier, 2019). These include calving, the initiation of lactation, diminished DMI, high nutrient demand, and the rapid mobilization of adipose tissue and muscle. The metabolic milieu created by early lactation creates hormonal and metabolic imbalance (low circulating blood insulin, glucose, and IGF1, and high fatty acid and BHB concentrations) that can lead to metabolic diseases including ketosis, fatty liver, and insulin resistance (Chagas et al., 2007; De Koster and Opsomer, 2013; Lucy et al., 2014). Metabolic disease can exacerbate immune dysfunction (Esposito et al., 2014; Sordillo, 2016; LeBlanc, 2020). Clinical and subclinical hypocalcemia may reduce DMI to further exacerbate hormonal and metabolic imbalance and also predisposes the cow to retained placenta (Lean et al., 2019). Retained placenta and immune dysfunction increase the likelihood that the cow will contract metritis shortly after calving (Beagley et al., 2010). Metritis predisposes the cow to endometritis and ultimately subclinical endometritis (LeBlanc, 2008). Cows with subclinical endometritis have uterine inflammation as evidenced by PMN within the uterine lumen (de Boer et al., 2014). High-producing (more than 35 $\mathrm{kg}$ ) dairy cows may be at greater risk for uterine disease if the stress caused by high milk production creates 
unresolved strain and metabolic imbalance (Williams, 2013).

Uterine disease early postpartum reduces fertility during the breeding period, typically after $60 \mathrm{~d}$ postpartum (LeBlanc, 2008, 2014; Gilbert, 2016). The mechanisms of how uterine disease affects fertility have been hypothesized (Sheldon et al., 2009a,b; LeBlanc, 2014; Eckel and Ametaj, 2016). One mechanism involves the residual effects of early postpartum uterine disease on the functional capacity of the uterus to support pregnancy. A second mechanism involves an indirect effect where uterine disease and the associated systemic inflammation damage the developing ovarian follicles to reduce their functionality or damage the oocytes themselves to reduce their capacity for fertilization or developmental competence after fertilization. We hypothesized that uterine disease would (1) compromise the growth and development of large ovarian follicles; (2) reduce the percentage of cows with functional embryos before d 18 after AI; and (or) (3) increase the loss of established pregnancies from 18 to $45 \mathrm{~d}$ after AI. To test these hypotheses, we categorized cows into 1 of 2 groups (with or without uterine disease) and evaluated the functionality of their ovaries when subjected to a timed AI protocol. We also evaluated the capacity of the cows to establish a pregnancy through d 18 after AI and maintain the pregnancy from 18 to $45 \mathrm{~d}$ after AI.

\section{MATERIALS AND METHODS}

The study followed the research animal care and welfare regulations established by the University of Missouri and was approved by the Institutional Animal Care and Use Committee.

\section{Cows and Study Design}

Postpartum lactating Holstein dairy cows located at the University of Missouri dairy (Midway, MO) were used. The trial was conducted during $2 \mathrm{yr}$, the first year from November 2014 to April 2015 ( $\mathrm{n}=51$ cows; 25 primiparous and 26 multiparous) and the second year from October 2015 to May 2016 ( $\mathrm{n}=51$ cows; 17 primiparous and 34 multiparous). Sixteen cows were common to both years (consecutive lactations). Cows were housed in a 4-row freestall barn with a grooved concrete floor and mattresses bedded with cedar shavings. Cows were fed a TMR composed of corn silage, alfalfa haylage, alfalfa hay, brewer's grains, soybean meal, soy hulls, dry corn, and mineral vitamin premix that was balanced to meet or exceed nutrient requirements defined by the NRC (2001). Cows were milked twice daily with an average daily milk production of $40.3 \pm 9.6 \mathrm{~kg} / \mathrm{d}$ (mean $\pm \mathrm{SD}$ ) during the trial periods.
Cows were organized into weekly cohorts between 30 to 39 DIM and treated with a timed AI program (Presynch Ovsynch 56) for AI at 68 to 77 DIM (Figure 1). Cows were treated with an i.m. injection of $\mathrm{PGF}_{2 \alpha}$ (PG1; $5 \mathrm{~mL}$ of Lutalyse; $25 \mathrm{mg}$ of dinoprost tromethamine; Zoetis Inc., Florham Park, NJ), and 14 d later a second i.m. injection of $\mathrm{PGF}_{2 \alpha}$ (PG2) was administered. Fourteen days after PG2, an i.m. injection of GnRH (GnRH1; $2 \mathrm{~mL}$ of Factrel; $100 \mu \mathrm{g}$ of gonadorelin; Zoetis Inc.) was administered. Seven days after GnRH1, a third i.m. injection of $\mathrm{PGF}_{2 \alpha}$ (PG3) was given at approximately $0800 \mathrm{~h}$ and a second i.m. injection of GnRH (GnRH2) was given $56 \mathrm{~h}$ after the PG3. The timed AI was $16 \mathrm{~h}$ after GnRH2. Cows were scored for body condition [BCS; 1 (thin) to 5 (obese); Edmondson et al., 1989] immediately after PG1, PG2, and PG3.

\section{Strategy for Assigning Cows to Uterine Diseased or Nondisease Groups Based on Endometrial Cytology}

Two endometrial cytology samples were collected per cow [one at PG1 (30 to 39 DIM) and a second on the afternoon before PG3 (64 to 73 DIM)] using a Cytobrush (CooperSurgical Inc., Berlin, Germany) (Kasimanickam et al., 2005). The handle of the Cytobrush was cut to a 3 - to 5 -cm length, threaded on to a $60-\mathrm{cm}$ steel rod and placed into an AI pipette with the steel rod in place of the plunger. The assembly was covered by an AI sheath (Continental Plastics Corp., Delavan, WI) and a plastic sanitary sleeve (Continental Plastics Corp.). The perineal region of the cow was cleaned with a paper towel. The cytology instrument was inserted through the vagina and cervix and into the uterine body by manipulating the reproductive tract transrectally. The plastic sleeve was pierced at the cervical interface. The Cytobrush was exposed to the uterine body by pushing it forward with the steel rod. The exposed Cytobrush was rotated 3 times against the uterine body wall. The Cytobrush was then retracted into the AI pipette and removed from the cow covered by the AI pipette and insemination sheath.

The Cytobrush was rotated on a clean microscope slide and fixed with CytoPrep fixative (Fisher Scientific Co., Pittsburgh, PA). The sample was air-dried and taken to the laboratory where it was stained with Protocol Hema 3 Stain Set (Fisher Scientific Co.) following the manufacturer's instructions. The stained slide was scored at $250 \times$ using a Laborlux S microscope (Leitz, Vila Nova de Famalico, Portugal). Each slide was read by a single examiner (R. M.-C.). One hundred cells (endometrial epithelial cells and PMN) were counted 


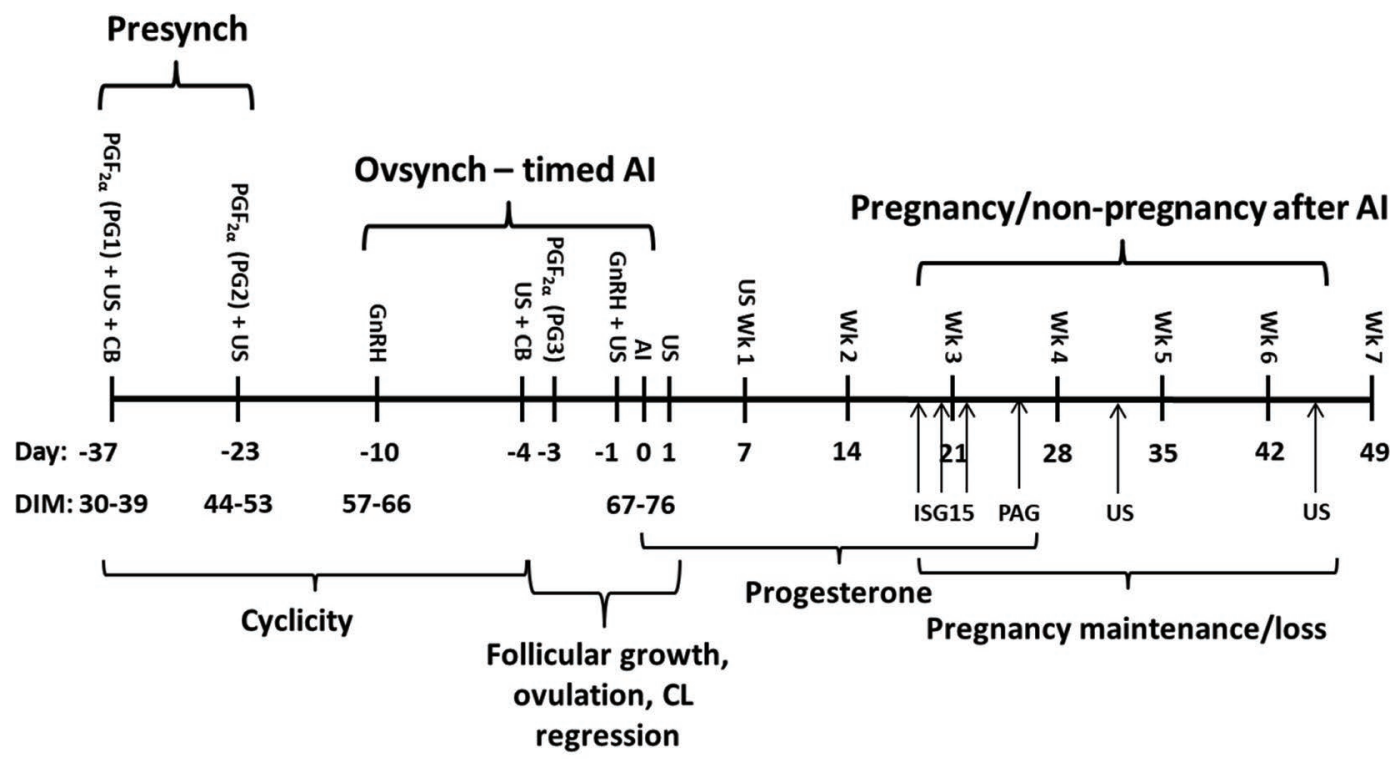

Figure 1. Timeline for the study for the effects of uterine disease on estrous cyclicity, ovarian function, and pregnancy in postpartum dairy cows. Dairy cows were assigned to healthy or diseased uterus statuses based on the percentage of polymorphonuclear neutrophils (PMN) in the uterine lumen determined by using a Cytobrush (CB; CooperSurgical Inc., Berlin, Germany) examination at the first (PG1) and on the afternoon before the third (PG3) $\mathrm{PGF}_{2 \alpha}$ injections. Data were collected by using an ovarian ultrasound (US) examination during the Presynch and Ovsynch timed AI periods. Plasma progesterone concentrations were measured at PG1, PG2, and on the afternoon before PG3 to assess cyclicity. Plasma progesterone was also measured on d 1, 4, 6, 8, 11, 13, 15, 18, 20, and 22 after timed AI (d 0). Pregnancy diagnosis was done by testing for ISG15 ratio and pregnancy-associated glycoprotein (PAG) expression and by using US on d 32 and 45 . CL = corpus luteum.

from 5 different random fields on each slide ( 20 cells per field). The total number of PMN divided by the total cells multiplied by 100 was defined as the percentage of PMN of the sample.

The mean \pm standard deviation for percentage of PMN was $11.7 \pm 22.6$ and $1.9 \pm 7.0$ for the first $(30$ to 39 DIM) and second (64 to 73 DIM) sample, respectively (Figure 2). The data were used to calculate an $\mathrm{SE}(\mathrm{SD} / \sqrt{ } \mathrm{N})$ and a $95 \%$ confidence interval $( \pm 1.96 \times$ SE) for the percentage of PMN that differed from $0 \%$ PMN in the sample. For the first sample, the samples with $\leq 4.4 \%$ PMN were within the $95 \%$ CI for $0 \%$ PMN and were defined as healthy. For the second sample, samples with $<1.4 \%$ PMN were within the $95 \%$ CI for $0 \% \mathrm{PMN}$ and were also defined as healthy. A cow was defined as healthy if both her first and second sample were defined as healthy $(\mathrm{n}=63 ; 20$ primiparous and 43 multiparous). If either her first $(\mathrm{n}=21)$ or second $(\mathrm{n}=$ $7)$ or both $(\mathrm{n}=11)$ samples were diseased then the cow was defined as diseased for study purposes $(\mathrm{n}=39 ; 22$ primiparous and 17 multiparous).

\section{Data Collection}

The experiment was organized into 4 specific periods for data collection (Figure 1). During the Presynch period, the primary objective was to determine if the cow was cycling [possessed a corpus luteum (CL)]. The Presynch period was followed by the Ovsynch timed AI where the primary purpose was the measurement of follicular growth, ovulation, and CL regression. Plasma progesterone concentrations were measured following the timed AI, and pregnancy maintenance or loss was assessed thereafter.

Ovarian Structure Evaluation by Ultrasound. Ovaries were imaged by using an ultrasound (Aloka SSD-500, Tokyo, Japan) equipped with a $7.5-\mathrm{MHz}$ probe during the Presynch period (on the day of PG1 and PG2) and during the Ovsynch timed AI period (on the afternoon before PG3, $2 \mathrm{~d}$ after PG3, and $4 \mathrm{~d}$ after PG3). Ovarian follicles were classified into 1 of 3 categories with respect to the follicular diameter (class 1: 2 to $5 \mathrm{~mm}$; class 2: 6 to $9 \mathrm{~mm}$; class $3: \geq 10 \mathrm{~mm}$ ). Follicles $>25 \mathrm{~mm}$ diameter were considered abnormal and were not counted as dominant or second largest follicles. A dominant follicle had to be $\geq 10 \mathrm{~mm}$ in diameter. Corpora lutea and fluid-filled center (if present) were also counted and measured. Ovulation was presumed to have occurred if a large $(>10 \mathrm{~mm})$ preovulatory follicle detected by ultrasound on the day of second GnRH (d -1 ) was not found at the next ultrasound examination one day after AI (d 1). Ovulation was confirmed by the appearance of a new CL $7 \mathrm{~d}$ after timed AI as determined by ultrasound. 
Analyses of Plasma Progesterone and IGF1. Blood samples were collected from coccygeal vessels on the day of ultrasound examinations and also 1, 4, 6, $8,11,13,15,18,20$, and $22 \mathrm{~d}$ after timed AI (Figure 1). The purpose of the blood collection was to use circulating progesterone concentrations to confirm cyclicity (Presynch period) and the functionality of the CL after AI. Samples were collected into 10-mL Vacutainer tubes [Monoject EDTA (K3) $0.10 \mathrm{~mL}$ of $15 \%$ EDTA solution; Covidien, Mansfield, MA] and immediately placed on ice before being brought to the laboratory. Blood samples were centrifuged at $1,500 \times g$ at $4^{\circ} \mathrm{C}$ for $15 \mathrm{~min}$. The plasma was collected and placed in polypropylene tubes and frozen at $-20^{\circ} \mathrm{C}$ for further analysis.

Concentrations of progesterone were measured by using a progesterone double antibody RIA kit manufactured by MP Biomedicals (catalog no. 07 170105, Irvine, CA) as described and validated by Pohler et al. (2016). The intra- and interassay coefficients of variation for progesterone assays were 8.7 and $6.8 \%$, respectively.

Plasma samples were also analyzed for IGF1 concentrations to assess the metabolic status of study
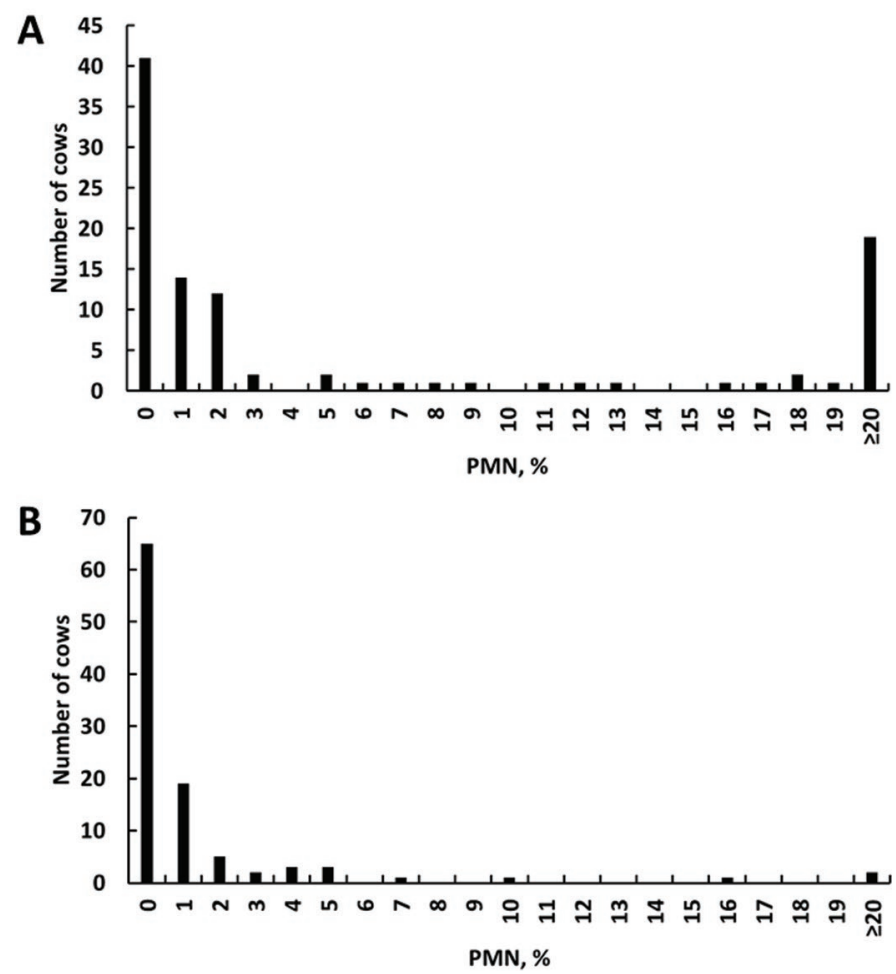

Figure 2. Frequency of cows with different percentages of polymorphonuclear neutrophils (PMN) in the uterine lumen recovered by using a Cytobrush (CooperSurgical Inc., Berlin, Germany). The first Cytobrush collection $(\mathrm{A} ; \mathrm{n}=102)$ was done at 30 to $39 \mathrm{DIM}$, and the second Cytobrush collection $(\mathrm{B} ; \mathrm{n}=102)$ was done at 64 to 73 DIM. cows. Plasma IGF1 concentrations were analyzed by validated RIA as described by Rhoads et al. (2008). The intra- and interassay coefficients of variation for IGF1 were 9.3 and $5.4 \%$, respectively.

Pregnancy Diagnosis. Pregnancy was assessed by 3 methods for all cows [interferon-stimulated gene 15 (ISG15)/peptidylprolyl isomerase A (PPIA or cyclophilin A; ISG15 ratio; d 18 to 22), pregnancyassociated glycoproteins (PAG; d 25), and transrectal ultrasound (d 32 and 45)] that enabled the determination of pregnancy from d 18 to 45 after AI (Figure 1). The ISG15 and PPIA expression in peripheral leukocyte RNA were measured using the method described by Green et al. (2010). The RNA was extracted from whole blood on d 18,20, and 22 after AI using the QIAamp RNA Blood Mini Kit (Qiagen, Hilden, Germany) and following the manufacturer's instructions. On-column DNase digestion was performed to remove genomic DNA. Once RNA was extracted and purified it was eluted twice in $30 \mu \mathrm{L}$ of RNase-free water. The absorbencies of the eluate at 260 and $280 \mathrm{~nm}$ were measured using a ND-1000 UV-Vis Spectrophotometer (NanoDrop Technologies, Wilmington, DE) and used to assess RNA purity and concentration. One microgram of RNA was electrophoresed through a $1.5 \%$ agarose gel in Tris-borate EDTA buffer $(0.09 M$ Tris-borate and $0.002 M$ EDTA) with ethidium bromide $(0.5 \mu \mathrm{g} / \mathrm{mL})$ to verify the integrity of each sample. Isolated RNA was stored at $-80^{\circ} \mathrm{C}$.

A high-capacity cDNA reverse transcription kit (Applied Biosystems, Foster City, CA) was used for cDNA synthesis. The cDNA samples were stored at $-20^{\circ} \mathrm{C}$ until real-time PCR. The 7500 Real Time PCR System (Applied Biosystems) was used for quantitative PCR. Twenty-microliter reactions contained the SYBR Green PCR Master Mix $(10 \mu \mathrm{L}), 10 \mu M$ forward and reverse primers for either ISG15 or PPIA (reference gene; Green et al., 2010), sample cDNA, and molecular biology water. Temperature cycles were $50^{\circ} \mathrm{C}$ for $2 \mathrm{~min}$ followed by $95^{\circ} \mathrm{C}$ for $10 \mathrm{~min}$ and 45 cycles of $95^{\circ} \mathrm{C}$ for 15 $\mathrm{s}$ and $60^{\circ} \mathrm{C}$ for $1 \mathrm{~min}$. A melting curve was performed at the end of each run to verify that a single amplicon was present. A 1:4 serial dilution of a single known sample was used to create a standard curve (high, medium, low, and null concentration) and was run in all plates in triplicate. Samples were run in duplicate. Relative expression of each gene was calculated based on the cycle threshold $\left(\mathbf{C}_{\mathbf{T}}\right)$ using the formula 2 ^ (the average $\mathrm{C}_{\mathrm{T}}$ of the medium dilution of the standard curve minus the average $\mathrm{C}_{\mathrm{T}}$ of the sample). The ISG15 expression was normalized by using a ratio to PPIA gene expression (Green et al., 2010). The ratio of ISG15/PPIA (ISG15 ratio) was used for the creation of receiver operating characteristic (ROC) curves and statistical analyses. 
The ISG15 ratio ROC curves were generated by using logistic regression in SAS (PROC LOGISTIC; version 9.4, SAS Institute Inc., Cary, NC). The event was the result of the PAG pregnancy diagnosis. The sensitivity (true positive rate) was defined as the proportion of pregnant cows that were correctly identified as pregnant for a given $I S G 15$ ratio cutpoint. The specificity was defined as the proportion of nonpregnant cows that were correctly identified as nonpregnant for a given $I S G 15$ ratio cutpoint. The $I S G 15$ ratio on d 18,20 , and 22 was tested independently in the analysis. The ROC curves themselves were created by using a macro as described in the SAS Knowledge Base (sample 25018: plot ROC curve with cutpoint labeling and optimal cutpoint analysis; http://support.sas.com/kb/25/018 .html). Cutpoints were selected that had the greatest sensitivity and specificity.

At d 25 after timed AI a plasma sample was used for pregnancy diagnosis by using a commercially available kit for PAG (Bovine Pregnancy Test Kit, IDEXX Laboratories Inc., Westbrook, ME). The test was done following the manufacturer's instructions for bovine plasma. Samples were run in duplicate.

Detection of a conceptus by ultrasound at d 32 after AI was done by veterinarians from the College of Veterinary Medicine of the University of Missouri. A second confirmatory ultrasound was done on d 45 after AI and was based on the presence of a conceptus with a beating heart. Ultrasound diagnoses were done by using an ultrasound (Aloka SSD-500) equipped with a $5-\mathrm{MHz}$ probe.

\section{Statistical Analysis}

Data were analyzed by using the 9.4 version of SAS software. All models included the effects of uterine disease (yes or no) as defined by cytological analysis, parity (primiparous or multiparous), and year. Tests for cyclicity at PG1, PG2, and PG3 were based on the presence of CL as detected by ultrasound or plasma progesterone concentrations greater than $1 \mathrm{ng} / \mathrm{mL}$ (indicative of a functional CL). The cyclicity data were coded as a binary variable $(0=$ no and $1=$ yes $)$ and analyzed by using logistic regression (Proc LOGISTIC of SAS). The number of follicles within specific diameter ranges, the diameter of the largest (dominant) follicle, and the diameter of the second largest follicle were analyzed during the Ovsynch timed AI period. Data were analyzed for the ultrasound exam conducted on the afternoon before PG3, at $2 \mathrm{~d}$ after PG3 (morning before GnRH2), and $4 \mathrm{~d}$ after PG3 (1.5 d after GnRH2). The diameter of the ovulatory follicle and percentage of cows ovulating were also reported for $4 \mathrm{~d}$ after PG3. Analyses of ovarian data from the Ovsynch timed AI period were done using Proc GLM with statistical models that included the effects of disease (yes or no), parity, and year. The concentrations of plasma progesterone after the timed AI and ISG15 ratio after AI were analyzed as repeated measures by using Proc MIXED of SAS. The model included the effects of disease, parity, pregnancy status, year, day, and the interactions of the main effects. Day was defined as repeated and cow was defined as a random effect. Pregnancy per AI (P/ AI; number of pregnant cows/number of inseminated cows) at d 18,20,22, 25,32, and 45 and embryonic loss rates (number of lost pregnancies/number initially pregnant) from d 18 to 20,20 to 22 , d 22 to 25 , d 25 to 32 , d 32 to 45 , and d 22 to 45 were tested using logistic regression as a binary variable $[0=$ not pregnant and $1=$ pregnant or $0=$ lost and $1=$ not lost (stayed pregnant), respectively]. The model included the effects of disease (yes or no), parity, and year. In all analyses, higher order interactions were tested and removed from the model if not significant. Statistical significance was declared at $P \leq 0.05$. Data are presented as least squares means \pm standard error of the mean, unless otherwise stated. Asterisk within graphs represent the results of the mean separation procedure PDIFF within Proc MIXED at $P<0.05$.

\section{RESULTS}

\section{General Characteristics of Cows Assigned to Healthy and Diseased Groups}

Based on herd records, the percentages of cows diagnosed with metritis, metabolic disease, lameness, other disease, or any disease were similar for cows that were later assigned to the healthy or diseased groups based on uterine cytology. For all cows, the overall percentage was $17 \%$ for metritis, $16 \%$ for metabolic disease, $11 \%$ for lameness, $22 \%$ for other, and $65 \%$ for any disease. Parity had an effect on the percentage of cows with metritis $[33 \%(14 / 42)$ for primiparous and 5\% (3/60) for multiparous], but other diseases were not affected by disease group, parity, or year. Milk production was less $(P<0.001)$ for primiparous compared with multiparous cows $(35.2 \pm 0.9$ vs. $43.1 \pm 0.8 \mathrm{~kg} / \mathrm{d})$ and was greater $(P<0.01)$ for healthy compared with diseased cows $(41.2 \pm 0.8$ vs. $37.1 \pm 0.9 \mathrm{~kg} / \mathrm{d})$. Milk fat percentage $(3.7 \pm 0.8)$ and milk protein percentage were not affected by disease, parity, or year. Body condition score decreased from PG1 to PG3 (3.19 \pm 0.04 BCS units, $3.20 \pm 0.04$ BCS units, and $3.03 \pm 0.04$ BCS units for PG1, PG2, and PG3; $P<0.001)$ and was greater $(P<$ 0.01 ) in primiparous compared with multiparous cows $(3.28 \pm 0.04$ vs. $3.00 \pm 0.04$ BCS units). Disease had no effect on postpartum BCS. 


\section{Cyclicity at PG1, PG2, and PG3}

The percentages of cows cycling at PG1, PG2, or PG3 were not affected by uterine disease status when the presence of a CL was detected by ultrasonography or based on plasma progesterone $\geq 1 \mathrm{ng} / \mathrm{mL}$ (Table 1 ). Neither parity nor year affected the percentage of cows cycling. For all cows, the percentage of cycling cows increased from PG1 [58 (59/102) and $47(48 / 102)]$ to PG3 [91 (93/102) and 84 (86/102); percentage (no./ no.) based on ultrasonography $(P<0.001)$ and plasma progesterone concentrations $(P<0.001)$, respectively].

\section{Ovarian Response During the Ovsynch Timed Al}

The number of follicles in different size classes on the afternoon before PG3, $2 \mathrm{~d}$ after PG3, and $4 \mathrm{~d}$ after PG3 was generally not affected by disease, parity, or year (Table 1 ). The only 2 exceptions were an effect of disease on the number of class 3 follicles at $4 \mathrm{~d}$ after
PG3 $(P<0.034$; Table 1$)$ and also a parity by disease interaction for number of class 1 follicles $(P<0.01)$ at $4 \mathrm{~d}$ after PG3 $(7.4 \pm 0.9$ and $11.2 \pm 0.9$ follicles for primiparous and $10.7 \pm 0.6$ and $9.3 \pm 0.9$ follicles for multiparous; healthy and diseased, respectively). No effects were observed for disease, parity, or year on the diameter of the largest or second largest follicle on any of the days (Table 1) or the ovulatory dominant follicle (measured $2 \mathrm{~d}$ after PG2). The proportion of cows ovulating after GnRH2 (93/102; 91\%) was not affected by disease, parity, or year (Table 1$)$. Plasma progesterone concentrations decreased $(P<0.001)$ from the afternoon before PG3 to $2 \mathrm{~d}$ after PG3 but were not affected by disease, parity, or year.

\section{Progesterone and IGF1 Concentrations After Timed Al}

Effects were observed for day $(P<0.001)$, pregnancy status by day interaction (Figure $3 \mathrm{~A} ; P<0.002$ ), and

Table 1. Percentage of cows cycling (cyclicity) at the time of the first (PG1), second (PG2), or third (PG3) injection of $\mathrm{PGF}_{2 \alpha}$ within a timed $\mathrm{AI}$ program and the number and diameter of ovarian follicles and plasma progesterone $(\mathrm{P} 4)$ concentrations preceding and following PG3 $(-1,+2$, and $+4 \mathrm{~d})$ for postpartum dairy cows that were assigned to healthy or diseased uterus statuses based on the percentage of PMN in the uterine lumen at PG1 and PG3 $(-1 \mathrm{~d})^{1}$

\begin{tabular}{|c|c|c|c|}
\hline Item & Healthy & Diseased & $P$-value \\
\hline \multicolumn{4}{|c|}{ Cyclicity (based on detection of CL by ultrasound) } \\
\hline Cows cycling at PG1, \% (no./no.) & $55.5(35 / 63)$ & $61.5(24 / 39)$ & NS \\
\hline Cows cycling at PG2, \% (no./no.) & $80.6(50 / 62)$ & $81.1(30 / 37)$ & NS \\
\hline Cows cycling at PG3, \% (no./no.) & $92.1(58 / 63)$ & $89.7(35 / 39)$ & NS \\
\hline \multicolumn{4}{|l|}{ Cyclicity (based on plasma $\mathrm{P} 4 \geq 1 \mathrm{ng} / \mathrm{mL}$ ) } \\
\hline Cows cycling at PG1, \% (no./no.) & $46.0(29 / 63)$ & $48.7(19 / 39)$ & NS \\
\hline Cows cycling at PG2, \% (no./no.) & $73.0(46 / 63)$ & $76.3(29 / 38)$ & NS \\
\hline Cows cycling at PG3, \% (no./no.) & $88.9(56 / 63)$ & $76.9(30 / 39)$ & NS \\
\hline \multicolumn{4}{|l|}{ Preovulatory follicular growth, CL regression } \\
\hline \multicolumn{4}{|l|}{ PG3 d -1 } \\
\hline $\mathrm{n}$ & 63 & 39 & \\
\hline Number of class 1 (2 to $5 \mathrm{~mm}$ ) follicles & $7.7 \pm 0.6$ & $8.0 \pm 0.7$ & NS \\
\hline Number of class 2 (6 to $9 \mathrm{~mm}$ ) follicles & $1.8 \pm 0.2$ & $1.7 \pm 0.2$ & NS \\
\hline Number of class $3(\geq 10 \mathrm{~mm})$ follicles & $1.9 \pm 0.2$ & $1.7 \pm 0.2$ & NS \\
\hline Largest follicle diameter, mm & $15.0 \pm 0.5$ & $14.3 \pm 0.6$ & NS \\
\hline Second largest follicle diameter, $\mathrm{mm}$ & $10.0 \pm 0.6$ & $9.7 \pm 0.7$ & NS \\
\hline Plasma P4 concentrations, ng/mL & $4.8 \pm 0.5$ & $4.9 \pm 0.5$ & NS \\
\hline \multicolumn{4}{|l|}{ PG3 + $2 \mathrm{~d}$} \\
\hline $\mathrm{n}$ & 63 & 39 & \\
\hline Number of class 1 ( 2 to $5 \mathrm{~mm}$ ) follicles & $7.0 \pm 0.6$ & $8.6 \pm 0.7$ & NS \\
\hline Number of class 2 (6 to $9 \mathrm{~mm}$ ) follicles & $1.4 \pm 0.2$ & $1.1 \pm 0.2$ & NS \\
\hline Number of class $3(>10 \mathrm{~mm})$ follicles & $2.0 \pm 0.2$ & $1.7 \pm 0.2$ & NS \\
\hline Largest follicle diameter, $\mathrm{mm}$ & $15.9 \pm 0.4$ & $14.7 \pm 0.6$ & NS \\
\hline Second largest follicle diameter, $\mathrm{mm}$ & $10.6 \pm 0.6$ & $10.8 \pm 0.8$ & NS \\
\hline Ovulatory follicle diameter, mm & $15.1 \pm 0.4$ & $15.3 \pm 0.4$ & NS \\
\hline Plasma P4 concentrations, $\mathrm{ng} / \mathrm{mL}$ & $0.4 \pm 0.1$ & $0.3 \pm 0.1$ & NS \\
\hline \multicolumn{4}{|l|}{ PG3 +4 d } \\
\hline $\mathrm{n}$ & 63 & 39 & \\
\hline Number of class 1 ( 2 to $5 \mathrm{~mm}$ ) follicles & $9.0 \pm 0.6$ & $10.2 \pm 0.7$ & NS \\
\hline Number of class 2 (6 to $9 \mathrm{~mm}$ ) follicles & $2.1 \pm 0.2$ & $1.7 \pm 0.3$ & NS \\
\hline Number of class $3(\geq 10 \mathrm{~mm})$ follicles & $0.9 \pm 0.1$ & $0.5 \pm 0.2$ & 0.034 \\
\hline Ovulation, \% (no./no.) & $92.1(58 / 63)$ & $89.7(35 / 39)$ & NS \\
\hline Plasma P4 concentrations, $\mathrm{ng} / \mathrm{mL}$ & $0.4 \pm 0.1$ & $0.3 \pm 0.1$ & NS \\
\hline
\end{tabular}

${ }^{1}$ Data are $\mathrm{LSM} \pm \mathrm{SEM} . \mathrm{CL}=$ corpus luteum. 
parity by day interaction (Figure 3B; $P<0.05$ ) for plasma progesterone concentrations after the timed AI. As expected, cows that tested pregnant on d 25 had increased plasma progesterone concentrations after $\mathrm{d}$ 15 of the cycle. First-parity cows had greater plasma progesterone concentrations from d 8 to 15 of the cycle. The disease by day interaction for plasma progesterone concentrations was not significant (Figure 3C). Plasma IGF1 concentrations (LSM \pm SEM) were greater for primiparous compared with multiparous cows (114.2 \pm 2.7 vs. $79.3 \pm 2.7 \mathrm{ng} / \mathrm{mL} ; P<0.001)$ but were lesser for healthy compared with diseased cows $(89.6 \pm 2.6$ vs. $103.9 \pm 2.7 \mathrm{ng} / \mathrm{mL} ; P<0.001)$. A pregnancy status by day interaction was observed for plasma IGF1 concentrations $(P<0.001$; Figure 3D). Cows that were not pregnant had greater plasma IGF1 concentrations on d 20 and 22 compared with pregnant cows.

\section{Pregnancy}

As expected, pregnancy status had an effect on the amount of $I S G 15$ ratio $(P<0.001$; Figure 4$)$ because cows that were diagnosed pregnant by PAG on d 25 had greater $I S G 15$ ratio on d 18, 20, and 22 compared with nonpregnant cows. Day had an effect on ISG15 ratio $(P<0.016)$ because the ratio on $\mathrm{d} 18$ was less $(0.046 \pm 0.07)$ than $d 20(0.67 \pm 0.07)$ or $d 22(0.62$ $\pm 0.07)$. The interaction of day and pregnancy status was not significant. The ISG15 ratio was greater in pregnant versus nonpregnant cows on each of d 18 (0.80 \pm 0.10 vs. $0.10 \pm 0.09), 20(1.11 \pm 0.10$ vs. $0.22 \pm$ $0.09)$, and $22(1.09 \pm 0.10$ vs. $0.14 \pm 0.09)$. An effect was observed of parity for ISG15 ratio $(P<0.013)$ because primiparous pregnant cows had greater ISG15 ratio than multiparous pregnant cows (Figure 4A). A pregnancy status by disease status interaction $(P<$ 0.001 ) was also observed. Pregnant diseased cows had greater $I S G 15$ ratio than pregnant healthy cows and nonpregnant diseased cows had lesser ISG15 ratio than nonpregnant healthy cows (Figure 4B).

The result of the PAG test on d 25 after AI was used to generate cutpoints for pregnancy diagnosis using ISG15 ratio with ROC curves. Optimal cutpoints maximized the sensitivity and specificity for the pregnancy diagnosis. Separate ROC curves were generated for yr 1 and yr 2 because a different control sample was used in the real-time PCR. For yr 1, the area under the ROC curve, sensitivity, specificity, and kappa values
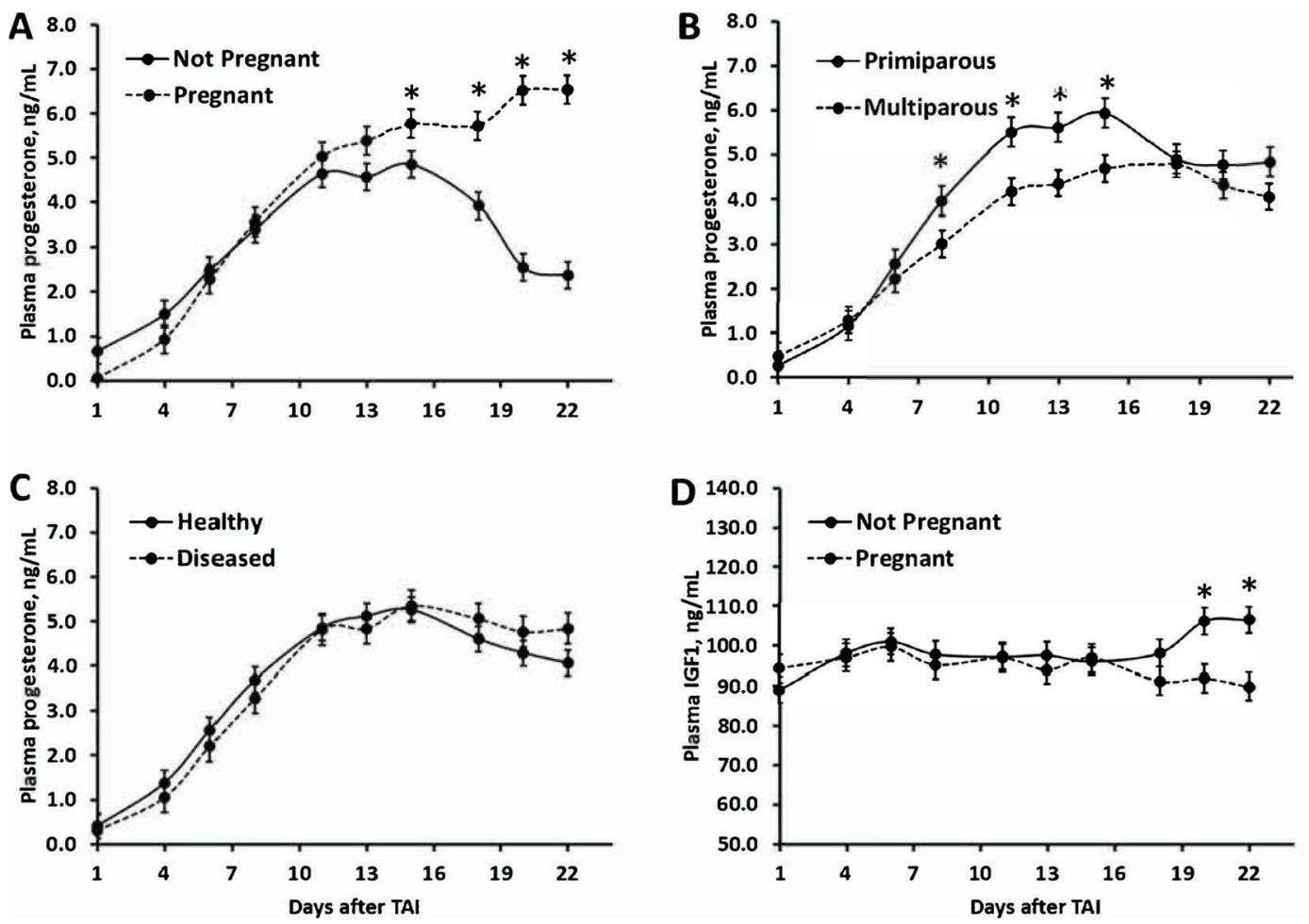

Figure 3. Least squares means and SEM (bar) for concentrations of plasma progesterone (A, B, and C) and IGF1 (D) for the first estrous cycle after a timed AI (67 to 76 DIM) in postpartum dairy cows that were either pregnant or not pregnant based on the d-25 pregnancyassociated glycoprotein test ( $\mathrm{A}$ and $\mathrm{D} ; \mathrm{n}=48$ pregnant and $\mathrm{n}=54$ not pregnant), primiparous or multiparous (B; $\mathrm{n}=42$ primiparous and $\mathrm{n}$ $=60$ multiparous $)$, or having a healthy or diseased uterus $\left(\mathrm{C} ; \mathrm{n}=63\right.$ healthy and $\mathrm{n}=39$ diseased). ${ }^{*} P<0.05$ for group comparison within day. TAI = timed artificial insemination 
were $0.94,0.91,0.80$, and 0.63 for d 18 ISG15 ratio; $0.95,0.95,0.83$, and 0.76 for d $20 I S G 15$ ratio; and 0.96 , $0.96,0.89$, and 0.80 for d $22 I S G 15$ ratio. For yr 2 , the area under the ROC curve, sensitivity, specificity, and kappa value were $0.89,0.78,0.89$, and 0.61 for $\mathrm{d} 18$ ISG15 ratio; $0.90,0.91,0.84$, and 0.69 for d 20 ISG15 ratio; and $0.94,0.92,0.92$, and 0.80 for d 22 ISG15 ratio. Cows testing positive for pregnancy based on $\mathrm{d}$ 22 ISG15 ratio had greater $(P<0.001)$ plasma progesterone concentrations compared with nonpregnant cows $(6.0 \pm 0.5$ vs. $2.4 \pm 0.5 \mathrm{ng} / \mathrm{mL}$, respectively).

Pregnancy per AI based on the ISG15 ratio, the PAG test, and ultrasound examination were similar for diseased versus healthy cows and were not affected by parity or year on each of d 18,20,22, 25, and 32 (Figure $5 \mathrm{~A})$. Parity and year did not affect $\mathrm{P} / \mathrm{AI}$ on d 45 after timed AI, but a decrease $(P<0.05)$ occurred in $\mathrm{P} / \mathrm{AI}$ on $\mathrm{d} 45$ in diseased but not in healthy cows. Embryonic loss rates (number lost/number initially pregnant) were similar for healthy and diseased cows when measured from d 18 to 20 , d 20 to 22 , d 22 to 25 , and 25 to 32 (Figure 5B). Embryonic loss from d 32 to 45 was greater $(P<0.02)$ in diseased $(4 / 12 ; 33.3 \%)$ compared with healthy $(1 / 27 ; 3.7 \%)$ cows (Figure $5 \mathrm{~B})$. The cumulative embryonic loss for cows diagnosed pregnant by ISG15 ratio on d 22 to the d 45 ultrasound examination was greater $(P<0.014)$ in diseased $(10 / 17 ; 58.8 \%)$ compared with healthy $(6 / 30 ; 20 \%)$ cows (Figure 5B).

\section{DISCUSSION}

Our first hypothesis was that uterine disease would compromise the growth and development of large ovarian follicles. We reject this hypothesis because we found that ovarian function as assessed by response to a timed AI program was minimally affected by uterine disease.
Cows that were categorized as having evidence of uterine disease had similar rates of cyclicity at specific intervals postpartum and a similar percentage ovulated following the timed AI program when compared with healthy cows (Table 1). The number of follicles within specific diameter classes were similar when studied during the preovulatory period. After ovulation (PG3 + $4 \mathrm{~d})$ there were fewer class 3 follicles in diseased cows, but this was the only difference that we detected for healthy compared with diseased for number or diameter of follicles. Following ovulation, plasma progesterone concentrations were similar for diseased and healthy cows (Figure 3C). The collective interpretation is that ovarian function as assessed by follicle number and sizes as well as progesterone concentrations during the luteal phase were not affected by uterine disease given the disease definition that we employed.

Our observations do not exclude the possibility that studies using different case definitions for uterine disease or earlier postpartum cows with active infections may have a different outcome and reach different conclusions. Previous studies that employed different case definitions and cows earlier postpartum have demonstrated an effect of uterine disease on ovarian function (Ribeiro et al., 2016). Sheldon et al. (2009a,b) cited studies that demonstrated slower growth of dominant follicles, reduced ovulation rate, and lesser peripheral concentrations of estradiol and progesterone in diseased cows. This previous work has largely focused on early postpartum cows with active infections. Our study differed from many of the aforementioned studies because we focused on ovarian function later postpartum (after approximately $70 \mathrm{~d}$ postpartum) and around the time of first breeding. The general conclusion that uterine disease affects ovarian function early but not later postpartum is supported by the work of Strüve et al.
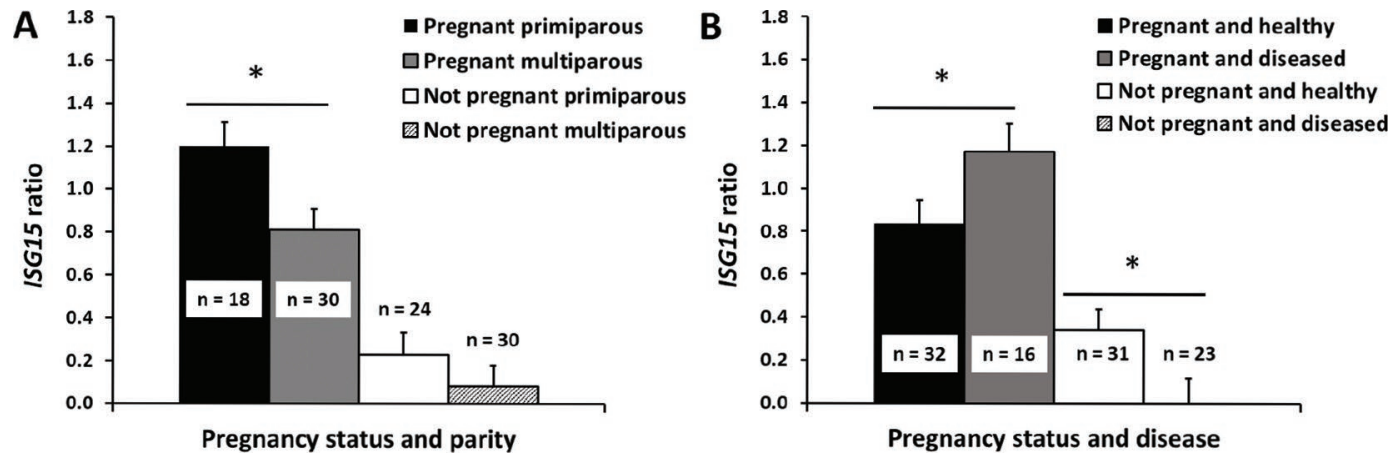

Figure 4. Least squares means and SEM (bar) for the ratio of ISG15 to PPIA (ISG15 ratio) after timed AI for primiparous and multiparous cows that were either pregnant or not pregnant (A) and for uterine healthy or diseased cows that were either pregnant or not pregnant (B). Data are main effects across all days (interactions with day were not significant; $P>0.10)$. Pregnancy status had an effect on $I S G 15$ ratio $(P<0.001$; pregnant greater than nonpregnant cows). In A, parity had an effect on ISG15 ratio in pregnant but not nonpregnant cows. In B, a disease status $\times$ pregnancy status interaction $(P<0.001)$ was observed. Pregnant diseased cows had greater ISG15 ratio than pregnant healthy cows, and nonpregnant diseased cows had a lesser ISG15 ratio than nonpregnant healthy cows. ${ }^{*} P<0.05$ for comparison of means within pregnancy status. 

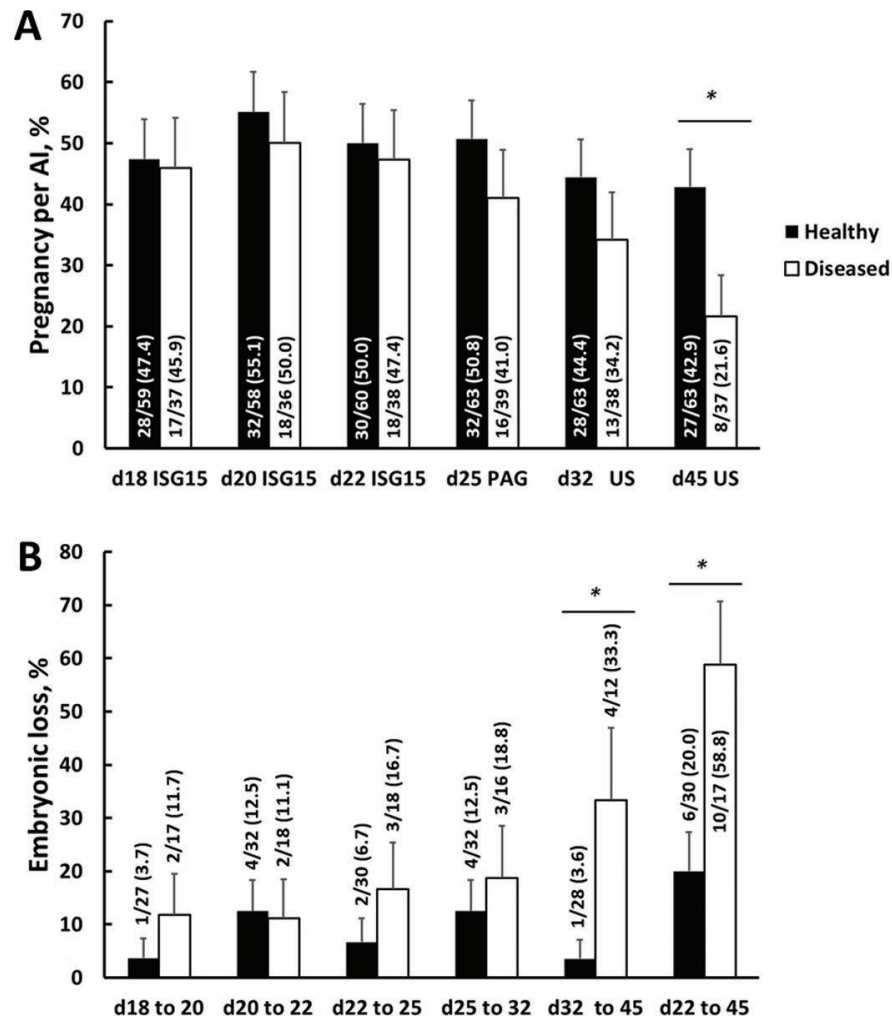

Figure 5. Pregnancy per AI $(100 \times$ no. of pregnant cows/no. of inseminated cows; bar $=$ SEM of the proportion) for uterine healthy and diseased cows based on pregnancy testing at 18,20,22, 25, 32, and $45 \mathrm{~d}$ after $\mathrm{AI}(\mathrm{A})$ and embryonic loss during different periods after AI (B). In A, data that are displayed vertically are the number of cows that tested pregnant/number of cows with test results (\%) for pregnancy diagnosis and are based on a test for ISG15 ratio (d 18, 20, and 22), pregnancy-associated glycoproteins (PAG; d 25), and ultrasonography (US; d 32 and 45). The total number of cows was 63 healthy and 39 diseased. Denominators in A with a lesser numbers reflect failed or missing tests on the specific day. In B, pregnancy loss was the number of lost pregnancies/number of original pregnancies (\%). For d 18 to 20, the number of original pregnancies was the number of pregnant cows on $\mathrm{d} 18$, and the number of lost pregnancies was the number of pregnant cows on d 18 that tested not pregnant on d 20 (lost pregnancy). Other intervals were calculated in an identical manner. Denominators in B with a lesser number reflect failed or missing tests on the second day of the interval. ${ }^{*} P<0.05$ for comparison of healthy versus diseased.

(2013) who observed effects of uterine disease on the first postpartum CL but not later postpartum CL.

The analysis of plasma progesterone concentrations after timed AI failed to demonstrate a difference between diseased and healthy cows (Figure 3C). We did find the expected difference in plasma progesterone concentrations for pregnant versus nonpregnant cows after AI. Pregnant cows had greater progesterone concentrations beginning on d 15 (Figure $3 \mathrm{~A}$ ). We also found that first-parity cows had greater circulating progesterone concentrations when compared with multiparous cows (Figure 3B). Greater milk progesterone concentrations for primiparous versus multiparous cows have been reported by others (Bruinjé et al., 2017). Our data and the data from Bruinjé et al. (2017) support the belief that higher-producing cows (in this case multiparous) have lesser circulating progesterone concentrations. Greater feed consumption in higher-producing cows increases hepatic blood flow and the metabolism of steroids to reduce circulating progesterone concentrations (Wiltbank et al., 2014).

Our second hypothesis was that uterine disease would reduce the percentage of cows with functional embryos before d 18 after AI. We again reject this hypothesis. Fertilization and the presence of a viable embryo are difficult to measure in dairy cattle before maternal recognition of pregnancy. We used an ISG15 ratio test at the earliest possible time (d 18 after AI) to do this. Production of interferon tau (IFNT) by the early embryo is associated with an increase in interferon-stimulated gene expression (Hansen et al., 2017). Several interferon-stimulated genes are suitable for testing and we selected ISG15 for this purpose (Green et al., 2010; Ott, 2019). The ISG15 is expressed as a ratio to the PPIA reference gene to control for RNA extraction and quantification (Green et al., 2010). Receiver operator characteristic curves were developed with specific cutpoints to determine pregnancy based on ISG15 ratio. Our observation that plasma progesterone concentrations were 2.5-fold greater in cows testing positive for pregnancy using $I S G 15$ ratio supported the validity of the test. We found that healthy and diseased cows were similar with respect to the number of pregnancies as early as d 18 after AI (Figure 5A). An identical conclusion was reached for $I S G 15$ ratio testing on d 20 and 22 . We cannot make definitive conclusions about fertilization rate or other developmental stages before $\mathrm{d} 18$, but it did appear that development can proceed through the period of maternal recognition of pregnancy within a uterus defined as diseased based on the criteria that we employed.

The ISG15 ratio testing confirmed some of the previous observations that we have made. The test using blood samples, for example, can be employed as early as d 18 after AI with sensitivity and specificity for pregnancy diagnosis above 90 and $80 \%$, respectively. The signal appears to be slightly stronger for d 20 and 22 compared with d 18 (effect of day in our analyses; $P<0.016)$. We also observed a greater ISG15 ratio for primiparous versus multiparous cows (Figure 4A). We observed this previously in our original studies of the ISG15 ratio test (Green et al., 2010). Older cattle have lesser ISG15 expression perhaps because the embryonic signal is less or leukocytes respond differently to INFT as the animal ages. It is also possible that the embryonic output of IFNT is equal in primiparous 
versus multiparous cows but the larger size of multiparous cows dilutes the IFNT per unit of blood. If true then the lesser blood IFNT concentration could lead to lesser ISG15 expression in leukocytes. We also made the unexpected finding that the ISG15 ratio was affected by an interaction between uterine disease and pregnancy status (Figure 4B). This interaction was explained by greater ISG15 ratio in diseased pregnant cows compared with healthy pregnant cows but lesser ISG15 ratio in diseased nonpregnant cows compared with healthy nonpregnant cows. Takino et al. (2016) reported results similar to ours where Borna virus 1-infected (seropositive) pregnant cows had greater ISG15 expression compared with seronegative pregnant cows (Takino et al., 2016). Takino et al. (2016) also observed lower P/AI in the infected cows. Their conclusion was that diseased cows may require greater INFT signaling (and hence greater ISG15) for the establishment of pregnancy. The greater ISG15 ratio response may also imply greater sensitivity of immune cells to IFNT within diseased cows. It is possible that previous infection has primed immune cells for the IFNT signal. This would be consistent with the central role that ISG proteins play in modulating the host response to pathogenesis (Perng and Lenschow, 2018).

The final hypothesis was that uterine disease would increase the loss of established pregnancies from 18 to $45 \mathrm{~d}$. We tentatively accept this hypothesis with the caveat that we studied a relatively small number of pregnancies. The period of greatest embryonic loss for diseased compared with healthy cows in the present study was between 32 and $45 \mathrm{~d}$ (Figure 5B). Many studies report lesser fertility and greater embryonic loss in cows with uterine disease (reviewed by LeBlanc 2008, 2014, 2020). In the study of Machado et al. (2015), for example, pregnancy was diagnosed on approximately d 30 and 65 . Pregnancy loss from d 30 to 65 was over 2 times greater in cows with uterine disease (clinical endometritis) postpartum. Ribeiro et al. (2013) reported that pregnancy loss during the same period was over 2 times greater in cows with metritis and over 4 times greater in cows with both metritis and clinical endometritis. Our observation of greater pregnancy loss after d 32 in diseased cows is consistent with the observations made in these larger field trials where ultrasound was used to study pregnancy loss in over 1,300 cows (Machado et al., 2015) and nearly 1,000 cows (Ribeiro et al., 2013).

Conclusions from our pregnancy data should be considered preliminary based on the relatively small number of cows enrolled in this study. It appeared that embryonic development can proceed through the period of IFNT secretion and maternal recognition of pregnancy that was defined by the $I S G 15$ ratio test. After this time, pregnancies in cows with evidence of uterine disease may be lost at a greater rate when compared with healthy cows. These new data agree with our published data on the relationship between uterine disease and the development of the conceptus (Lucy et al., 2016). We sampled uteri from lactating Holstein cows on d 28, 35, and 42 of pregnancy and scored the uteri for the amount of inflammation (Lucy et al., 2016). There was an association between the weight of the placenta and the amount of inflammation in the uterus (smaller placenta in cows with more uterine inflammation). We noted in the previous work that the most highly significant effects of inflammation were for the d 42 pregnancies, the latest pregnancy time point that we examined. This period of embryonic loss coincides with a period of rapid development of the placenta (d 35 to 60; Wiltbank et al., 2016). We concluded in our original work that the pregnancy develops normally before $\mathrm{d} 35$ and then the pregnancy does not develop further within a uterus that is compromised by previous uterine disease and inflammation. The conclusion from our previous work is similar to the one that we are tentatively making from the present work given the relatively small number of pregnancies that we examined.

Based on our limited number of pregnancies, there was a numerical (nonsignificant) difference in $\mathrm{P} / \mathrm{AI}$ for diseased versus healthy cows from d 22 to 32 . The cumulative loss of pregnancies from d 22 to 45 for diseased cows $(58.8 \%)$ was over 2.5 -fold greater than healthy cows $(20 \%)$ with the greatest loss in diseased cows occurring after d 32 (Figure 5B). The pregnancy data that we collected from d 22 to 32 did not achieve statistical significance, but the larger studies of Machado et al. (2015) and Ribeiro et al. (2013) demonstrated an effect of uterine disease on P/AI before d 30 and embryonic loss between d 30 and 65 (lesser P/AI before d 30 and greater embryonic loss after d 30 in diseased cows). In the present study, we found some evidence, albeit nonsignificant, to support embryonic loss from d 22 to 32 and did find evidence for a period of embryonic loss after d 32 (Figure 5).

We measured IGF1 concentrations as an indirect assessment of metabolic state of the study cows. Primiparous cows had greater IGF1 concentrations when compared with multiparous cows. This observation agrees with previous studies (Taylor et al., 2004; Grimard et al., 2013). Cows as well as humans undergo a process of "somatopause" where the somatotropic axis declines with age, yielding lower IGF1 concentrations in older individuals (Junnila et al., 2013). We also noted greater circulating IGF1 concentrations in cows classified as diseased compared with healthy. The greater circulating IGF1 concentrations were associated with lesser milk production in the diseased cows. Disease 
is generally associated with lesser milk production in postpartum cows and lower fertility but not greater circulating IGF1 concentrations (Overton et al., 2017). Fertility, for example, is typically found to be positively correlated with circulating IGF1 concentrations (Taylor et al., 2004; Patton et al., 2007; Velazquez et al., 2008). Although counterintuitive, fertility measured at the herd level may be positively correlated with milk production because healthy cows produce more milk and are also more likely to become pregnant (Nebel and McGilliard, 1993). Although the diseased cows in this experiment did not show overt signs of disease, they nonetheless produced less milk and the lesser milk production was associated with greater IGF1 concentrations. The greater IGF1 concentrations in lower milk-producing cows is the expectation given the mechanisms that control IGF1 expression within the somatotropic axis of lactating cows (Lucy, 2008).

We calculated a standard error and a 95\% confidence interval for the \% PMN in the study cows at each Cytobrush exam. Based on the confidence interval, diseased cows had a \% PMN that differed from $0 \%$ PMN. There were 20 primiparous and 43 multiparous healthy cows and 22 primiparous and 17 multiparous diseased cows. Whereas primiparous cows comprised approximately one-third of the healthy group, approximately equal numbers of primiparous and multiparous cows were present in the diseased group. Based on herd records, a higher percentage of primiparous compared with multiparous cows were diagnosed with metritis. This may have influenced the ratio of primiparous to multiparous cows in the healthy and diseased groups. Dystocia is a risk factor for metritis and uterine disease postpartum (LeBlanc, 2014). We did not record dystocia in this study but primiparous compared with multiparous cows are known to have a greater incidence of dystocia (Bonneville-Hébert et al., 2011). If there was more dystocia in the primiparous cows that we studied, then this would theoretically lead to more metritis and disease in the primiparous cows.

Cytobrush sampling was done at the first $\mathrm{PGF}_{2 \alpha}$ injection (PG1) and the third $\mathrm{PGF}_{2 \alpha}$ injection (PG3). More cows were cycling at PG3 compared with PG1 (presence of a CL and plasma progesterone $\geq 1 \mathrm{ng} /$ $\mathrm{mL}$; Table 1). Two studies failed to find a significant difference in the number of PMN within the uterus of estrus versus diestrus cows (Lander Chacin et al., 1990; Subandrio et al., 2000), but stage of cycle effects are nonetheless possible. The synchronization program that we used is designed to group cows into the early luteal phase at PG3. We may have found different \% PMN had cows been sampled at a different phase of the estrous cycle. Our analysis assumes that a disease by stage of cycle interaction for \% PMN within the uterus does not exist and that the primary factor affecting the $\%$ PMN was the presence of uterine disease.

\section{CONCLUSIONS}

Cows objectively assigned to a healthy uterus or diseased uterus status were assessed for ovarian follicular and luteal function around the time of AI and early embryonic development from d 18 to 45 after AI. We failed to identify a major effect of uterine disease on follicular or luteal function for these cows that were managed with a timed AI program. Percentages of healthy and diseased cows that were pregnant were similar from $d$ 18 to 22 after AI. The cumulative embryonic loss after d 22 was greater in diseased compared with healthy cows, but this observation was based on a small number of pregnancies and should be studied further in larger trials with greater statistical power. This period of embryonic loss that we observed coincides with a period of rapid placental development that apparently is not compatible with uterine disease.

\section{ACKNOWLEDGMENTS}

The authors express their gratitude to the undergraduate and graduate students from the University of Missouri and employees of Foremost Dairy (Midway, $\mathrm{MO})$ for the assistance in data collection and the management and insemination of cows. We also thank D. H. Keisler (University of Missouri) for performing the progesterone and IGF1 analyses. Funding was received from the Food for the 21st Century Program (University of Missouri). Graduate studies of the lead author were supported by Fulbright-Laspau (Cambridge, MA) and the University of Costa Rica. The authors have not stated any conflicts of interest.

\section{REFERENCES}

Beagley, J. C., K. J. Whitman, K. E. Baptiste, and J. Scherzer. 2010. Physiology and treatment of retained fetal membranes in cattle. J. Vet. Intern. Med. 24:261-268. https://doi.org/10.1111/j.1939-1676 .2010.0473.x.

Bonneville-Hébert, A., E. Bouchard, D. D. Tremblay, and R. Lefebvre. 2011. Effect of reproductive disorders and parity on repeat breeder status and culling of dairy cows in Quebec. Can. J. Vet. Res. 75:147-151.

Bruinjé, T. C., M. Gobikrushanth, M. G. Colazo, and D. J. Ambrose 2017. Dynamics of pre- and post-insemination progesterone profiles and insemination outcomes determined by an in-line milk analysis system in primiparous and multiparous Canadian Holstein cows. Theriogenology 102:147-153. https://doi.org/10.1016/ j.theriogenology.2017.05.024.

Chagas, L. M., J. J. Bass, D. Blache, C. R. Burke, J. K. Kay, D. R. Lindsay, M. C. Lucy, G. B. Martin, S. Meier, F. M. Rhodes, J. R. Roche, W. W. Thatcher, and R. Webb. 2007. Invited review: New perspectives on the roles of nutrition and metabolic priorities in the subfertility of high-producing dairy cows. J. Dairy Sci. 90:4022-4032. https://doi.org/10.3168/jds.2006-852. 
de Boer, M. W., S. J. LeBlanc, J. Dubuc, S. Meier, W. Heuwieser, S. Arlt, R. O. Gilbert, and S. McDougall. 2014. Invited review: Systematic review of diagnostic tests for reproductive-tract infection and inflammation in dairy cows. J. Dairy Sci. 97:3983-3999. https: //doi.org/10.3168/jds.2013-7450.

De Koster, J. D., and G. Opsomer. 2013. Insulin resistance in dairy cows. Vet. Clin. North Am. Food Anim. Pract. 29:299-322. https: //doi.org/10.1016/j.cvfa.2013.04.002.

Eckel, E. F., and B. N. Ametaj. 2016. Invited review: Role of bacterial endotoxins in the etiopathogenesis of periparturient diseases of transition dairy cows. J. Dairy Sci. 99:5967-5990. https://doi.org/ 10.3168/jds.2015-10727.

Edmonson, A. J., I. J. Lean, L. D. Weaver, T. Farver, and G. Webster. 1989. A body condition scoring chart for Holstein dairy cows. J. Dairy Sci. 72:68-78. https://doi.org/10.3168/jds.S0022 -0302(89)79081-0.

Esposito, G., P. C. Irons, E. C. Webb, and A. Chapwanya. 2014. Interactions between negative energy balance, metabolic diseases, uterine health and immune response in transition dairy cows. Anim. Reprod. Sci. 144:60-71. https://doi.org/10.1016/j.anireprosci.2013 .11 .007 .

Gilbert, R. O. 2016. Management of reproductive disease in dairy cows. Vet. Clin. North Am. Food Anim. Pract. 32:387-410. https: //doi.org/10.1016/j.cvfa.2016.01.009.

Green, J. C., C. S. Okamura, S. E. Poock, and M. C. Lucy. 2010. Measurement of interferon-tau (IFN-tau) stimulated gene expression in blood leukocytes for pregnancy diagnosis within 18-20d after insemination in dairy cattle. Anim. Reprod. Sci. 121:24-33. https: //doi.org/10.1016/j.anireprosci.2010.05.010.

Grimard, B., B. Marquant-Leguienne, D. Remy, C. Richard, F. Nuttinck, P. Humblot, and A. A. Ponter. 2013. Postpartum variations of plasma IGF and IGFBPs, oocyte production and quality in dairy cows: Relationships with parity and subsequent fertility. Reprod. Domest. Anim. 48:183-194. https://doi.org/10.1111/j.1439 -0531.2012.02127.x.

Gross, J. J., and R. M. Bruckmaier. 2019. Review: Metabolic challenges in lactating dairy cows and their assessment via established and novel indicators in milk. Animal 13(S1):s75-s81. https://doi .org/10.1017/S175173111800349X.

Hansen, T. R., L. D. P. Sinedino, and T. E. Spencer. 2017. Paracrine and endocrine actions of interferon tau (IFNT). Reproduction 154:F45-F59. https://doi.org/10.1530/REP-17-0315.

Junnila, R. K., E. O. List, D. E. Berryman, J. W. Murrey, and J. J. Kopchick. 2013. The GH/IGF-1 axis in ageing and longevity. Nat. Rev. Endocrinol. 9:366-376. https://doi.org/10.1038/nrendo.2013 .67 .

Kasimanickam, R., T. F. Duffield, R. A. Foster, C. J. Gartley, K. E. Leslie, J. S. Walton, and W. H. Johnson. 2005. A comparison of the cytobrush and uterine lavage techniques to evaluate endometrial cytology in clinically normal postpartum dairy cows. Can. Vet. J. 46:255-259.

Lander Chacin, M. F., P. J. Hansen, and M. Drost. 1990. Effects of stage of the estrous cycle and steroid treatment on uterine immunoglobulin content and polymorphonuclear leukocytes in cattle. Theriogenology 34:1169-1184. https://doi.org/10.1016/S0093 -691X(05)80016-0.

Lean, I. J., J. E. P. Santos, E. Block, and H. M. Golder. 2019. Effects of prepartum dietary cation-anion difference intake on production and health of dairy cows: A meta-analysis. J. Dairy Sci. 102:21032133. https://doi.org/10.3168/jds.2018-14769.

LeBlanc, S. 2010. Monitoring metabolic health of dairy cattle in the transition period. J. Reprod. Dev. 56(Suppl):S29-S35. https://doi .org/10.1262/jrd.1056S29.

LeBlanc, S. J. 2008. Postpartum uterine disease and dairy herd reproductive performance: A review. Vet. J. 176:102-114. https://doi .org/10.1016/j.tvjl.2007.12.019.

LeBlanc, S. J. 2014. Reproductive tract inflammatory disease in postpartum dairy cows. Animal 8(Suppl 1):54-63. https://doi.org/10 $.1017 / \mathrm{S} 1751731114000524$
LeBlanc, S. J. 2020. Review: Relationships between metabolism and neutrophil function in dairy cows in the peripartum period. Animal 14(S1):s44-s54. https://doi.org/10.1017/S1751731119003227.

Lucy, M. C. 2008. Functional differences in the growth hormone and insulin-like growth factor axis in cattle and pigs: implications for post-partum nutrition and reproduction. Reprod. Domest. Anim. 43(Suppl 2):31-39. https://doi.org/10.1111/j.1439-0531.2008 $.01140 . x$.

Lucy, M. C., S. T. Butler, and H. A. Garverick. 2014. Endocrine and metabolic mechanisms linking postpartum glucose with early embryonic and foetal development in dairy cows. Animal 8(Suppl 1):82-90. https://doi.org/10.1017/S1751731114000482.

Lucy, M. C., T. J. Evans, and S. E. Poock. 2016. Lymphocytic foci in the endometrium of pregnant dairy cows: Characterization and association with reduced placental weight and embryonic loss. Theriogenology 86:1711-1719. https://doi.org/10.1016/j.theriogenology .2016.05.030.

Machado, V. S., G. Oikonomou, E. K. Ganda, L. Stephens, M. Milhomem, G. L. Freitas, M. Zinicola, J. Pearson, M. Wieland, C. Guard, R. O. Gilbert, and R. C. Bicalho. 2015. The effect of intrauterine infusion of dextrose on clinical endometritis cure rate and reproductive performance of dairy cows. J. Dairy Sci. 98:38493858. https://doi.org/10.3168/jds.2014-9046.

NRC. 2001. Nutrient Requirements of Dairy Cattle. 7th rev. ed. Natl Acad. Sci., Washington, DC.

Nebel, R. L., and M. L. McGilliard. 1993. Interactions of high milk yield and reproductive performance in dairy cows. J. Dairy Sci. 76:3257-3268. https://doi.org/10.3168/jds.S0022-0302(93)77662 $-6$.

Ott, T. L. 2019. Symposium review: Immunological detection of the bovine conceptus during early pregnancy. J. Dairy Sci. 102:37663777. https://doi.org/10.3168/jds.2018-15668.

Overton, T. R., J. A. McArt, and D. V. Nydam. 2017. A 100-Year Review: Metabolic health indicators and management of dairy cattle. J. Dairy Sci. 100:10398-10417. https://doi.org/10.3168/jds .2017-13054.

Patton, J., D. A. Kenny, S. McNamara, J. F. Mee, F. P. O'Mara, M. G. Diskin, and J. J. Murphy. 2007. Relationships among milk production, energy balance, plasma analytes, and reproduction in Holstein-Friesian cows. J. Dairy Sci. 90:649-658. https://doi.org/ 10.3168/jds.S0022-0302(07)71547-3.

Perng, Y.-C., and D. J. Lenschow. 2018. ISG15 in antiviral immunity and beyond. Nat. Rev. Microbiol. 16:423-439. https://doi.org/10 .1038/s41579-018-0020-5.

Pohler, K. G., M. H. C. Pereira, F. R. Lopes, J. C. Lawrence, D. H. Keisler, M. F. Smith, J. L. M. Vasconcelos, and J. A. Green. 2016. Circulating concentrations of bovine pregnancy-associated glycoproteins and late embryonic mortality in lactating dairy herds. J Dairy Sci. 99:1584-1594. https://doi.org/10.3168/jds.2015-10192.

Rhoads, M. L., J. P. Meyer, W. R. Lamberson, D. H. Keisler, and M. C. Lucy. 2008. Uterine and hepatic gene expression in relation to days postpartum, estrus, and pregnancy in postpartum dairy cows. J. Dairy Sci. 91:140-150. https://doi.org/10.3168/jds.2007-0439.

Ribeiro, E. S., G. Gomes, L. F. Greco, R. L. A. Cerri, A. Vieira-Neto, P. L. J. Monteiro Jr., F. S. Lima, R. S. Bisinotto, W. W. Thatcher, and J. E. P. Santos. 2016. Carryover effect of postpartum inflammatory diseases on developmental biology and fertility in lactating dairy cows. J. Dairy Sci. 99:2201-2220. https://doi.org/10.3168/ jds.2015-10337.

Ribeiro, E. S., F. S. Lima, L. F. Greco, R. S. Bisinotto, A. P. A. Monteiro, M. Favoreto, H. Ayres, R. S. Marsola, N. Martinez, W. W. Thatcher, and J. E. P. Santos. 2013. Prevalence of periparturient diseases and effects on fertility of seasonally calving grazing dairy cows supplemented with concentrates. J. Dairy Sci. 96:5682-5697. https://doi.org/10.3168/jds.2012-6335.

Sheldon, I. M., J. Cronin, L. Goetze, G. Donofrio, and H.-J. Schuberth. 2009a. Defining postpartum uterine disease and the mechanisms of infection and immunity in the female reproductive tract in cattle. Biol. Reprod. 81:1025-1032. https://doi.org/10.1095/biolreprod 109.077370 
Sheldon, I. M., S. B. Price, J. Cronin, R. O. Gilbert, and J. E. Gadsby. 2009b. Mechanisms of infertility associated with clinical and subclinical endometritis in high producing dairy cattle. Reprod. Domest. Anim. 44(Suppl 3):1-9. https://doi.org/10.1111/j.1439 $-0531.2009 .01465 . x$.

Sordillo, L. M. 2016. Nutritional strategies to optimize dairy cattle immunity. J. Dairy Sci. 99:4967-4982. https://doi.org/10.3168/jds .2015-10354.

Strüve, K., K. Herzog, F. Magata, M. Piechotta, K. Shirasuna, A. Miyamoto, and H. Bollwein. 2013. The effect of metritis on luteal function in dairy cows. BMC Vet. Res. 9:244. https://doi.org/10 .1186/1746-6148-9-244.

Subandrio, A. L., I. M. Sheldon, and D. E. Noakes. 2000. Peripheral and intrauterine neutrophil function in the cow: The influence of endogenous and exogenous sex steroid hormones. Theriogenology 53:1591-1608. https://doi.org/10.1016/S0093-691X(00)00300-9.

Takino, T., T. Okamura, T. Ando, and K. Hagiwara. 2016. Change in the responsiveness of interferon-stimulated genes during early pregnancy in cows with Borna virus-1 infection. BMC Vet. Res. 12:253. https://doi.org/10.1186/s12917-016-0883-5.

Taylor, V. J., Z. Cheng, P. G. A. Pushpakumara, D. C. Wathes, and D. E. Beever. 2004. Relationships between the plasma concentrations of insulin-like growth factor-I in dairy cows and their fertility and milk yield. Vet. Rec. 155:583-588. https://doi.org/10.1136/vr 155.19 .583

Velazquez, M. A., L. J. Spicer, and D. C. Wathes. 2008. The role of endocrine insulin-like growth factor-I (IGF-I) in female bovine reproduction. Domest. Anim. Endocrinol. 35:325-342. https://doi .org/10.1016/j.domaniend.2008.07.002.

Williams, E. J. 2013. Drivers of post-partum uterine disease in dairy cattle. Reprod. Domest. Anim. 48(Suppl 1):53-58. https://doi .org/10.1111/rda.12205.

Wiltbank, M. C., G. M. Baez, A. Garcia-Guerra, M. Z. Toledo, P. L. J. Monteiro, L. F. Melo, J. C. Ochoa, J. E. P. Santos, and R. Sartori. 2016. Pivotal periods for pregnancy loss during the first trimester of gestation in lactating dairy cows. Theriogenology 86:239-253. https://doi.org/10.1016/j.theriogenology.2016.04.037.

Wiltbank, M. C., A. H. Souza, P. D. Carvalho, A. P. Cunha, J. O. Giordano, P. M. Fricke, G. M. Baez, and M. G. Diskin. 2014 Physiological and practical effects of progesterone on reproduction in dairy cattle. Animal 8(Suppl 1):70-81. https://doi.org/10.1017/ S1751731114000585.

\section{ORCIDS}

R. Molina-Coto () https://orcid.org/0000-0003-3844-2587

S. G. Moore (ㄱ https://orcid.org/0000-0001-9896-8519

W. R. Lamberson () https://orcid.org/0000-0001-5690-9860

S. E. Poock @ https://orcid.org/0000-0003-1178-0316

M. C. Lucy ำ https://orcid.org/0000-0001-5771-9460 